\title{
Validity of protein, retinol, folic acid and $n-3$ fatty acid intakes estimated from the food-frequency questionnaire used in the Danish National Birth Cohort
}

\author{
Tina B Mikkelsen ${ }^{1, *}$, Merete Osler ${ }^{2}$ and Sjurdur F Olsen ${ }^{1}$ \\ ${ }^{1}$ Maternal Nutrition Group, Danish Epidemiology Science Centre, Statens Serum Institut, Artillerivej 5, DK-2300 \\ Copenhagen S, Denmark: ${ }^{2}$ Department of Social Medicine, Institute of Public Health, University of Copenhagen, \\ Denmark
}

Submitted 14 June 2005: Accepted 13 October 2005

\begin{abstract}
Objective: To validate intakes of protein, folic acid, retinol and $n-3$ fatty acids estimated from a food-frequency questionnaire in week 25 of pregnancy (FFQ-25).

Design: Validation was done against a 7-day weighed food diary (FD) and biomarkers of the nutrients in gestation week 32-38.

Subjects and setting: The FFQ-25 to be validated was used in the Danish National Birth Cohort comprising 101042 pregnant Danish women, of whom 88 participated in the present validation study.

Results: Estimated intakes of protein, retinol and folic acid did not differ significantly between the two dietary methods, but intake of $n-3$ fatty acids was one third larger when estimated from the FFQ-25. The intakes estimated from the two dietary methods were all significantly correlated, ranging from 0.20 for retinol intake to 0.57 for folic acid intake. Sensitivities of being correctly classified into low and high quintiles were between 0.22 and 0.77 , and specificities were between 0.62 and 0.89 . Urinary protein content did not correlate significantly with protein estimated from the FFQ $(r=0.17, P>0.05)$, but did with intake estimated from the FD $(r=0.56, P<0.0001)$. Erythrocyte folate correlated significantly with the estimated total intake from the FFQ $(r=0.55, P<0.0001)$ and the FD $(r=0.52$, $P<0.0001)$. No correlations with plasma retinol were found. Erythrocyte eicosapentaenoic acid (C20:5n-3) correlated significantly with $n-3$ fatty acids intake estimated from both the FFQ-25 $(r=0.37, P<0.001)$ and the FD $(r=0.62$, $P<0.0001$ ).

Conclusion: The FFQ-25 gives reasonable valid estimates of protein, retinol and folic acid intakes, but seems to overestimate intake of $n-3$ fatty acids.
\end{abstract}

A number of hypotheses on the influence of maternal diet during pregnancy on health have been suggested during the last two decades. In Denmark, data on the dietary intake of pregnant women have been collected on a large scale in the Danish National Birth Cohort (DNBC), which is a prospective pregnancy cohort with national coverage ${ }^{1}$. In gestation week 25, a 360-item food-frequency questionnaire (FFQ-25) was mailed to all cohort members. To enable sensible use of these dietary data for aetiological analyses, however, we need information on the validity of the collected dietary information. The questionnaire is a modified version of the food-frequency questionnaire (FFQ) developed at the Danish Cancer Registry ${ }^{2}$, which was validated in a population of 40-64-year-old men and women ${ }^{3}$ and young non-pregnant women ${ }^{4}$. Since diet during pregnancy could be different and since pregnant women might be more aware of their dietary habits, it is important to validate the questionnaire in this particular population and describe the degree of misclassification.

Hypotheses initially motivating the set-up of the cohort included those regarding the potential influences of $\operatorname{protein}^{5-8}$, vitamin $\mathrm{A}^{9,10}$, folic $\operatorname{acid}^{11,12}$ and $n-3$ fatty acids ${ }^{13,14}$ consumed in pregnancy on pregnancy outcomes and various measures of offspring health. In the current paper we present results from a validation study pertaining to these nutrients. Intakes of protein, retinol, folic acid and marine $n-3$ fatty acids estimated from the FFQ-25 used in the DNBC were compared with intakes estimated from a 7-day weighed food diary (FD) and with biomarkers of the nutrients. 


\section{Materials and methods}

\section{Danish National Birtb Cobort}

The DNBC has recruited 101047 women in early pregnancy for long-term follow-up. The cohort is described in detail elsewhere ${ }^{1}$. In the present study dietary information was collected by means of a 360-item semi-quantitative FFQ mailed in gestation week 25 (FFQ-25), covering the woman's diet during the last 4 weeks. For items such as apples, glasses of beverage, etc., the women were asked about intake of natural units. For items with no natural units such as lasagne, corn, etc., the women were asked about frequency of intake. The frequency intervals ranged from no times during the past 4 weeks to more than 8 times a day. Open questions were asked about fats on bread and in cooking, salad dressings and dietary supplements. To estimate nutrient intakes, standard portion sizes and standard recipes have been developed. The frequency categories were calculated into times per day by using the midpoint (e.g. '1-2 times per week' was used in the calculations as 1.5 times per week/7 days per week). The software program FoodCalc, which is freely available on the Internet (www.foodcalc.dk), was used to assess daily intakes of nutrients. Intake of dietary supplements is very common among pregnant Danish women, especially multivitamins, which contain retinol and folic acid. Intake of dietary supplements was coded according to brand name. Information on the content of vitamins and minerals in the legal products was obtained from the Danish Veterinary and Food Administration, the Danish Medicines Agency and from producers of dietary supplements. If the woman took more than one product with the same vitamin, the total intake from all dietary supplements was calculated. The total retinol intake in $\mu \mathrm{g}$ was calculated as the sum of the estimated dietary intake and the intake from dietary supplements for both the FFQ-25 and the FD. Folic acid in dietary supplements is better absorbed than dietary folic acid ${ }^{15}$; therefore the use of dietary folate equivalents (DFE) is recommended. Unfortunately, a number of calculation methods are reported; one study ${ }^{15}$ suggests multiplying the folic acid amount in supplements by 1.7 while another ${ }^{16}$ suggests multiplying by 2 . In the present study we decided to multiply the intake from dietary supplements by 2 , i.e. $1 \mu \mathrm{g}$ folic acid from a dietary supplement is equal to $2 \mu \mathrm{g}$ DFE.

\section{Validation study}

A validation study of women who had completed the FFQ was carried out in gestation week 32-38, i.e. 2-3 months after completion of the FFQ-25. The validation study included a 7-day consecutive weighed FD, one 24-h urine collection and fasting blood samples. A weighed 7-day FD was chosen as the reference method because this method has fewest errors correlated with the FFQ ${ }^{17}$. The women received oral and written guidance on how to complete the food diary and the urine collection and a scale was provided for each woman. All questionnaires were checked upon receipt. FoodCalc and the Danish food tables and individual portion sizes and recipes were used to calculate nutrient intakes when possible, otherwise standard portion sizes and new recipes that matched the description of the food were used. We made 615 new standard recipes and 475 individual recipes (on average, 5.4 (range $0-14$ ) individual recipes per woman). Many of the new standard recipes were new products on the market not included in the Danish food tables. The individual recipes were the women's recipes whose ingredients were weighed or natural units stated (e.g. 1 egg).

\section{Biomarkers}

Biomarkers of intake of the four nutrients investigated were assessed in fasting blood samples and 24-h urine samples.

\section{Protein}

Urinary nitrogen excretion was measured using an NA 1500 instrument (Carlo Erba Strumentazione, Milan, Italy). It was decided not to give the women $p$-aminobenzoic acid (PABA) for the following reasons: (1) it could negatively affect the participation rate, because the pregnant women might be afraid to consume a drug; (2) there is no convincing evidence that it is not dangerous for the foetus; and (3) animal studies ${ }^{18}$ and an in vitro human study $^{19}$ have shown that PABA can cross the placenta this would result in less PABA in the urine, and thus recovery would not be measured accurately. Eighteen women reported to have missed one or more toilet visits (20\%), and one gave up sampling because of pelvic pains.

\section{Vitamin A}

Retinol in plasma was quantified by high-performance liquid chromatography on a LaChrom system (MerckHitachi, Darmstadt, Germany).

\section{Folic acid}

Erythrocyte folic acid level was determined using the AutoDELFIATM Folate kit from Perkin-Elmer (Wallac OY, Finland).

\section{n-3 Fatty acids}

Erythrocyte eicosapentaenoic acid (EPA, C20:5n-3) was determined as a biomarker for $n-3$ fatty acids intake. Erythrocyte phospholipids were extracted from the haemolysate using chloroform-methanol (2:1 v/v), followed by acid transmethylation. Separation of fatty acids was achieved by gas-liquid chromatography on a capillary CP-WAX58 column (Chrompack BV, Middelburg, The Netherlands).

\section{Subjects}

Participants living in Odense, who were in gestation week 30-31 and had completed the FFQ-25, were invited by 
mail to participate in the validation study. They were recruited in groups every two weeks from March to September 2001. We invited 256 women, of whom 94 agreed to participate. Six women did not start or finish the records, thus in total 88 women completed the study. Urine was collected on day 7 of the dietary registration and fasting blood samples were taken the next morning. One woman did not complete the urine collection and another woman could not have a blood sample drawn.

\section{Statistical analyses}

The intakes estimated from both dietary methods for protein, retinol, folic acid and $n-3$ fatty acids were not normally distributed, but the log-transformed intakes were. The total intakes of retinol and folic acid were not normally distributed, while the biomarker levels were. Comparisons were also made for nutrient density to reduce variation due to individual differences in total energy.

Comparisons of the amount of nutrients estimated from the FFQ-25 and from the FD were made by paired $t$-tests. All correlations are Pearson correlation coefficients of the log-transformed intakes, except for correlations with total intakes of retinol and folic acid for which Spearman correlations were used. Intakes of nutrients from dietary supplements were not continuous; e.g. most women took $400 \mu \mathrm{g}$ folic acid per day. All women were classified into quintiles according to their intakes of the four nutrients, estimated by both dietary methods. We calculated sensitivity and specificity of classifying the women correctly into the same and adjacent quintiles by the FFQ-25, with FD estimates as the gold standard. Furthermore, we assessed sensitivity and specificity of being correctly classified into the extreme quintiles. The mean 'true' value (estimated from the FD) in FFQ quintiles of intake was calculated, and the trend in true intake with FFQ quintiles was assessed using the PROC GLM procedure in SAS (SAS Institute, Cary, NC, USA), with quintile number as a continuous variable. Statistically significant differences between the mean of the lowest and the highest quintile were assessed using $t$-tests.

\section{Results}

Participants were slightly younger and more likely to be primiparous than the DNBC population in general (Table 1). Apart from that, participants seemed to be reasonably representative with respect to pre-pregnancy weight, body mass index, height and smoking habit.

\section{Estimated intakes}

Estimated $n-3$ fatty acid intake, expressed both per day and per $100 \mathrm{MJ}$ (density), was significantly higher when based on the FFQ (Table 2). Estimated intakes of other nutrients did not differ significantly between the dietary methods.

\section{Correlations between the two dietary methods}

All correlations between the two dietary methods were significant (Table 2). The weakest were seen for dietary retinol and $n-3$ fatty acids.

\section{Quintiles of dietary intake}

According to classification into quintiles of intake, between 56\% (retinol in diet $(\mu \mathrm{g})$, per day) and $84 \%$ (total folate intake (DFE), per $10 \mathrm{MJ}$ ) of subjects were classified in the same or adjacent quintile (Table 2).

The sensitivity of being correctly classified into the first, the two first, the highest and the two highest quintiles is presented in Table 3. For instance, 35\% of the participants who were 'truly' in quintile 1 of protein intake would be detected using the FFQ-25 estimates (sensitivity). Eightyfive per cent of participants who were 'truly' not in quintile 1 did not rank into quintile 1 based on the FFQ-25 (specificity).

\section{Comparisons with biomarkers}

The average values of biomarkers are shown in Table 4. The protein content in one sample of 24-h urine was not correlated with protein intake estimated from the FFQ-25 in terms of $\mathrm{g}$ per day $(r=0.17, P>0.05)$ or per $10 \mathrm{MJ}(r=0.20, P>0.05)$, but was correlated with

Table 1 Background characteristics of subjects who participated in the validation study, those who were invited but did not participate, and the population of the Danish National Birth Cohort (DNBC)

\begin{tabular}{|c|c|c|c|c|c|c|}
\hline \multirow[b]{3}{*}{ Background variable } & \multicolumn{4}{|c|}{ Women selected for the validation study } & \multirow{2}{*}{\multicolumn{2}{|c|}{$\begin{array}{c}\text { Cohort members } \\
\text { DNBC }(n=66868)\end{array}$}} \\
\hline & \multicolumn{2}{|c|}{ Participants $(n=88)$} & \multicolumn{2}{|c|}{ Non-participants $(n=168)$} & & \\
\hline & Median & $\mathrm{P}_{25}-\mathrm{P}_{75}$ & Median & $P_{25}-P_{75}$ & Median & $\mathrm{P}_{25}-\mathrm{P}_{75}$ \\
\hline Age (years) & 28.0 & $25.0-31.5$ & 29.0 & $26.0-32.0$ & $29.0^{*}$ & $26.0-32.0$ \\
\hline Pre-pregnancy weight (kg) & 64 & $58-71$ & 67 & $59-75$ & 65 & $58-73$ \\
\hline Height (cm) & 168 & $164-172$ & 168 & $164-173$ & 169 & $165-173$ \\
\hline Body mass index $\left(\mathrm{kg} \mathrm{m}^{-2}\right)$ & 22.5 & $20.8-24.9$ & 23.0 & $20.9-26.3$ & 22.6 & $20.7-25.4$ \\
\hline Parity (\% primiparous) & 55 & - & 45 & - & 41 & - \\
\hline Smokers (\% yes) & 17 & - & 12 & - & 13 & - \\
\hline
\end{tabular}

$\mathrm{P}_{25}-25$ th percentile; $\mathrm{P}_{75}-75$ th percentile.

${ }^{\star} P<0.05$ compared with participants in the validation study. 
Table 2 Comparisons between intakes estimated on the basis of the 360-item semi-quantitative food-frequency questionnaire at gestation week 25 (FFQ-25) and the 7-day weighed food diary (FD)

\begin{tabular}{|c|c|c|c|c|c|c|c|c|}
\hline \multirow[b]{2}{*}{ Estimated intake } & \multicolumn{2}{|c|}{ FFQ-25† } & \multicolumn{2}{|c|}{ FD† } & \multicolumn{2}{|c|}{$\begin{array}{l}\text { Spearman corre- } \\
\text { lation } \\
\text { coefficient }\end{array}$} & \multicolumn{2}{|c|}{$\begin{array}{l}\text { Concordance (\% } \\
\text { classified into the } \\
\text { same or adjacent } \\
\text { quintile) }\end{array}$} \\
\hline & Per day & Per $10 \mathrm{MJ}$ & Per day & Per $10 \mathrm{MJ}$ & Per day & Per $10 \mathrm{MJ}$ & Per day & Per $10 \mathrm{M}$ \\
\hline Energy (MJ day ${ }^{-1}$ ) & $10.6 \pm 3.1$ & - & $11.4 \pm 2.2$ & - & $0.43^{\star * \star}$ & - & 68 & - \\
\hline Protein $\left(\mathrm{g} \mathrm{day}^{-1}\right)$ & $91 \pm 24$ & $87 \pm 13$ & $91 \pm 20$ & $80 \pm 12^{\star \star \star}$ & $0.39^{\star \star}$ & $0.44^{\star \star \star}$ & 60 & 67 \\
\hline \multicolumn{9}{|l|}{ Retinol } \\
\hline Diet $\left(\mu \mathrm{g} \mathrm{day}^{-1}\right)$ & $708 \pm 540$ & $640 \pm 403$ & $642 \pm 414$ & $558 \pm 306$ & $0.27^{\star *}$ & $0.20^{*}$ & 56 & 61 \\
\hline Supplements ( $\mu \mathrm{g} \mathrm{day}^{-1}$ ) & $551 \pm 380$ & $551 \pm 380$ & $498 \pm 329$ & $498 \pm 329$ & $0.53^{\star * *}$ & $0.53^{\star \star \star}$ & - & - \\
\hline Total intake $\left(\mu \mathrm{g} \mathrm{day}^{-1}\right)$ & $1258 \pm 624$ & $1190 \pm 502$ & $1143 \pm 516$ & $1050 \pm 444$ & $0.37^{\star \star}$ & $0.41^{\star \star \star}$ & 65 & 73 \\
\hline \multicolumn{9}{|l|}{ Folic acid } \\
\hline Diet $\left(\mu\right.$ gday $\left.^{-1}\right)$ & $334 \pm 98$ & $321 \pm 72$ & $361 \pm 112^{*}$ & $320 \pm 84$ & $0.35^{\star *}$ & $0.50^{\star \star \star}$ & 74 & 75 \\
\hline Supplements ( $\mu \mathrm{g} \mathrm{day}^{-1}$ ) & $241 \pm 163$ & $241 \pm 163$ & $242 \pm 163$ & $242 \pm 163$ & $0.56^{\star * *}$ & $0.56^{\star \star \star}$ & - & - \\
\hline Total intake (DFE day ${ }^{-1}$ ) & $816 \pm 344$ & $803 \pm 343$ & $840 \pm 352$ & $799 \pm 347$ & $0.53^{\star \star \star}$ & $0.57^{\star \star *}$ & 77 & 84 \\
\hline$n-3$ Fatty acids $\left(\right.$ g day $\left.^{-1}\right)$ & $0.54 \pm 0.48$ & $0.50 \pm 0.35$ & $0.43 \pm 0.40^{* *}$ & $0.37 \pm 0.33^{\star \star \star}$ & $0.28^{* *}$ & $0.25^{\star}$ & 66 & 60 \\
\hline
\end{tabular}

DFE - dietary folate equivalents.

Significance: ${ }^{*}, P<0.05 ;{ }^{\star \star}, P<0.01 ;{ }^{* \star *}, P<0.0001$.

$\dagger$ Mean \pm standard deviation.

protein intake from the FD (average over the last week) in $\mathrm{g}$ per day $(r=0.64, P<0.0001)$ and per $10 \mathrm{MJ}$ $(r=0.40, P<0.0001)$. Retinol intake estimated from the FFQ-25 or from the FD was not significantly correlated with plasma retinol. Total intake of folic acid was correlated with erythrocyte folic acid in both the FFQ$25(r=0.55, P<0.0001)$ and the FD $(r=0.52$, $P<0.0001)$. A weaker correlation was seen for estimated intake from the diet and a stronger correlation with intake from dietary supplements (data not shown). The estimated intake of $n-3$ fatty acids from both the FFQ-25 $(r=0.37, P<0.001)$ and the FD $(r=0.62, P<0.0001)$ was significantly correlated with erythrocyte EPA.

\section{Mean estimated intakes based on FD and mean biomarker measurements according to quintiles of FFQ-based estimates}

The ability of the FFQ-25 to calculate the 'true intake' (in the present paper, the intake estimated from the FD) was also examined by calculating the mean intake from the FD in each quintile of intake estimated from the FFQ-25 (Table 5). Thus, a significantly lower 'true' mean intake was found in quintile 1 compared with quintile 5 for protein $\left(\mathrm{g} \mathrm{day}^{-1}\right)$, total retinol intake $\left(\mu \mathrm{g} \mathrm{day}^{-1}\right)$, folate $\left(\mathrm{DFE} \mathrm{day}^{-1}\right)$ and $n-3$ fatty acids $\left(\mathrm{g} \mathrm{day}^{-1}\right)$, but not for folic acid $\left(\mu \mathrm{g} \mathrm{day}^{-1}\right)$, in the diet. The same was seen when adjusted to energy (data not shown). There was a significant trend of increasing mean 'true intake' with increasing quintile for all nutrients except

Table 3 Comparisons between intakes estimated on the basis of the 360-item semi-quantitative food-frequency questionnaire at gestation week 25 and the 7-day weighed food diary

\begin{tabular}{|c|c|c|c|c|c|c|c|c|c|}
\hline \multirow[b]{2}{*}{ Nutrient } & & \multicolumn{4}{|c|}{ Sensitivity† } & \multicolumn{4}{|c|}{ Specificity† } \\
\hline & & Q1 & $\mathrm{Q} 1+\mathrm{Q} 2$ & Q5 & Q4 + Q5 & Q1 & $\mathrm{Q} 1+\mathrm{Q} 2$ & Q5 & Q4 + Q5 \\
\hline \multicolumn{10}{|l|}{ Protein } \\
\hline From diet (g) & per day & 0.35 & 0.46 & 0.35 & 0.58 & 0.85 & 0.64 & 0.85 & 0.71 \\
\hline & per $10 \mathrm{MJ}$ & 0.22 & 0.51 & 0.47 & 0.60 & 0.81 & 0.66 & 0.86 & 0.66 \\
\hline \multicolumn{10}{|l|}{ Retinol } \\
\hline \multirow[t]{2}{*}{ From diet $(\mu \mathrm{g})$} & per day & 0.22 & 0.46 & 0.41 & 0.44 & 0.81 & 0.62 & 0.85 & 0.63 \\
\hline & per $10 \mathrm{MJ}$ & 0.39 & 0.47 & 0.33 & 0.46 & 0.84 & 0.63 & 0.83 & 0.62 \\
\hline \multirow[t]{2}{*}{ Total intake $(\mu \mathrm{g})$} & per day & 0.47 & 0.56 & 0.41 & 0.54 & 0.81 & 0.71 & 0.84 & 0.68 \\
\hline & per $10 \mathrm{MJ}$ & 0.29 & 0.63 & 0.44 & 0.63 & 0.82 & 0.74 & 0.86 & 0.75 \\
\hline \multicolumn{10}{|l|}{ Folic acid } \\
\hline \multirow[t]{2}{*}{ From diet $(\mu \mathrm{g})$} & per day & 0.29 & 0.63 & 0.29 & 0.61 & 0.83 & 0.74 & 0.83 & 0.75 \\
\hline & per $10 \mathrm{MJ}$ & 0.59 & 0.61 & 0.35 & 0.63 & 0.89 & 0.73 & 0.83 & 0.74 \\
\hline \multirow[t]{2}{*}{ Total intake (DFE) } & per day & 0.39 & 0.69 & 0.47 & 0.66 & 0.86 & 0.79 & 0.87 & 0.77 \\
\hline & per $10 \mathrm{MJ}$ & 0.39 & 0.77 & 0.47 & 0.74 & 0.84 & 0.85 & 0.87 & 0.83 \\
\hline \multicolumn{10}{|l|}{$n-3$ Fatty acids } \\
\hline \multirow{2}{*}{ From diet (g) } & per day & 0.31 & 0.60 & 0.28 & 0.50 & 0.82 & 0.74 & 0.83 & 0.65 \\
\hline & per $10 \mathrm{MJ}$ & 0.33 & 0.53 & 0.22 & 0.50 & 0.84 & 0.69 & 0.81 & 0.65 \\
\hline
\end{tabular}

DFE - dietary folate equivalents.

$\dagger$ Sensitivities and specificities of being correctly classified into the first (Q1), the two lowest (Q1 + Q2), the last (Q5) and the two highest quintiles (Q4 + Q5) for the four nutrients. 
Table 4 Comparisons between biomarker levels and the corresponding nutrient intakes estimated on the basis of the 360-item semiquantitative food-frequency questonnaire at gestation week 25 (FFQ-25) and the weighed food diary (FD)

\begin{tabular}{|c|c|c|c|c|c|}
\hline & \multirow[t]{2}{*}{ Level† } & \multicolumn{2}{|c|}{$\begin{array}{l}\text { Correlation with dietary intake } \\
\text { estimated from the FFQ-25 }\end{array}$} & \multicolumn{2}{|c|}{$\begin{array}{l}\text { Correlationwith dietary intake } \\
\text { estimated from the FD }\end{array}$} \\
\hline & & Per day & Per MJ & Per day & Per $10 \mathrm{MJ}$ \\
\hline Urinary protein g /day & $72 \pm 16$ & $0.17^{(1)}$ & $0.20^{(1)}$ & $0.64^{\star \star \star(1)}$ & $0.40^{\star \star *(1)}$ \\
\hline Plasma retinol $\mu \mathrm{g} / \mathrm{ml}$ & $0.42 \pm 0.10$ & $-0.03^{(2)}$ & $-0.04^{(2)}$ & $-0.008^{(2)}$ & $0.04^{(2)}$ \\
\hline Erythrocyte folic acid & $708 \pm 227$ & $0.55^{\star \star \star(3)}$ & $0.58^{\star \star \star(3)}$ & $0.52^{\star \star \star(3)}$ & $0.54^{\star \star *(3)}$ \\
\hline Erythrocyte EPA & $0.51 \pm 0.19$ & $0.37^{\star \star(4)}$ & $0.36^{\star *(4)}$ & $0.62^{\star \star \star(4)}$ & $0.60^{\star \star \star(4)}$ \\
\hline
\end{tabular}

EPA - eicosapentaenoic acid; DFE - dietary folate equivalents.

Significance: ${ }^{* \star}, P<0.01 ;{ }^{* *}, P<0.0001$

$\dagger$ Mean \pm standard deviation of biomarket measurements.

$\mp$ Spearman correlation coefficients.

(1) Protein g; ${ }^{(2)}$ Total retinol $\mu \mathrm{g} ;{ }^{(3)}$ Total folic acid DFE; ${ }^{(4)} \mathrm{n}-3$ fatty acids $\mathrm{g}$

$n-3$ fatty acid intake. When calculating mean level of the biomarkers in each quintile based on the FFQ, quintiles of total folic acid (DFE day ${ }^{-1}$ ), protein $\left(\mathrm{g} \mathrm{day}^{-1}\right)$ and $n-3$ fatty acids $\left(\mathrm{g} \mathrm{day}^{-1}\right)$ intake showed a significant trend of increasing mean biomarker level with increasing quintile (Table 5) and no trend in mean plasma retinol level with increasing quintile of retinol intake.

\section{Discussion}

The results of the present paper indicate that the intakes of protein, retinol and folic acid estimated from the FFQ-25 were reasonably valid estimates, but for $n-3$ fatty acids the intake estimated from the FFQ was one third larger than that estimated from the FD.

Strengths of the study include that we had both food diaries and biomarkers to evaluate the validity. Moreover, we applied several different statistical methods to evaluate the associations, i.e. correlation coefficients between FFQ25 nutrient estimates and both FD nutrient estimates and biomarker levels, average intake from the FD and biomarker level for each quintile classified from the FFQ-25, and sensitivity and specificity of being correctly classified into the first and the highest quintile compared with the FD. A weakness was that the FD, for practical reasons, was administered 2-3 months after the FFQ-25, with the FFQ-25 covering 4 weeks retrospectively and the FD covering 1 week prospectively. We therefore expect to have underestimated the degree of validity in the present study.

The different ways of expressing validity of protein intake all indicated that the protein intake estimated from the FFQ-25 is valid. Correlation between the two dietary methods was within the expected range $(r=0.44, \quad P<0.0001)$; others have found weaker correlations $s^{3,4,20-24}$ and higher correlations among women ${ }^{25-29}$. The intake estimated from the FFQ-25 did not correlate with protein excretion (Table 4) but one 24-h urine sample is a short-term biomarker of intake; therefore protein excretion was expected to correlate with FD estimates of intake, if valid. A highly significant correlation of 0.64 was found between intake estimated from the FD and the biomarker level, which is higher than the correlation found in another study ${ }^{24}$. This may be due to the overlapping periods of time. Others have found a significant correlation of protein estimated from

Table 5 Level of daily intake of the four nutrients estimated from the 7-day weighed food diary (FD) and corresponding measurements of biomarkers according to quintiles defined by intakes estimated from the 360 -item semi-quantitative food-frequency questionnaire at gestation week 25 (FFQ-25)

\begin{tabular}{|c|c|c|c|c|c|c|c|}
\hline \multirow[b]{2}{*}{ Nutrient } & \multicolumn{5}{|c|}{ Level in quintiles on the basis of the FFQ-25 } & \multirow[b]{2}{*}{ Q1 vs. Q5 } & \multirow[b]{2}{*}{$P$ for trenc } \\
\hline & Q1 & Q2 & Q3 & Q4 & Q5 & & \\
\hline \multicolumn{8}{|l|}{ Protein } \\
\hline Intake from FD $\left(\mathrm{g} \mathrm{day}^{-1}\right)$ & $78 \pm 13$ & $88 \pm 18$ & $90 \pm 18$ & $98 \pm 26$ & $100 \pm 18$ & 0.0004 & 0.0004 \\
\hline Urinary protein $\left(\mathrm{g}\right.$ day $\left.^{-1}\right)$ & $66 \pm 16$ & $67 \pm 15$ & $75 \pm 14$ & $74 \pm 17$ & $75 \pm 15$ & 0.09 & 0.03 \\
\hline \multicolumn{8}{|l|}{ Retinol } \\
\hline Total intake from FD ( $\left.\mu \mathrm{g} \mathrm{day}^{-1}\right)$ & $898 \pm 338$ & $1037 \pm 423$ & $1070 \pm 394$ & $1206 \pm 363$ & $1499 \pm 781$ & 0.008 & 0.0004 \\
\hline Plasma retinol level $\left(\mu \mathrm{g} \mathrm{ml}^{-1}\right)$ & $0.45 \pm 0.12$ & $0.39 \pm 0.11$ & $0.42 \pm 0.08$ & $0.44 \pm 0.11$ & $0.42 \pm 0.10$ & 0.81 & 0.64 \\
\hline \multicolumn{8}{|l|}{ Folic acid } \\
\hline Total intake from FD $\left(\mu \mathrm{g} \mathrm{day}^{-1}\right)$ & $598 \pm 338$ & $696 \pm 367$ & $863 \pm 236$ & $873 \pm 352$ & $1177 \pm 133$ & $<0.0001$ & $<0.0001$ \\
\hline $\begin{array}{l}\text { Erythrocyte folate level }\left(\mathrm{nmol} \mathrm{I}^{-1} \text { ) }\right. \\
n-3 \text { Fatty acids }\end{array}$ & $569 \pm 221$ & $611 \pm 187$ & $684 \pm 185$ & $791 \pm 122$ & $905 \pm 268$ & 0.0008 & $<0.0001$ \\
\hline \multicolumn{8}{|l|}{$n-3$ Fatty acids } \\
\hline Erythrocyte EPA content (\%) & $0.43 \pm 0.15$ & $0.50 \pm 0.15$ & $0.53 \pm 0.27$ & $0.51 \pm 0.17$ & $0.60 \pm 0.16$ & 0.003 & 0.012 \\
\hline
\end{tabular}

EPA - eicosapentaenoic acid. 
an FFQ with urinary nitrogen ${ }^{24,25,27,30-32}$, but they used more than one 24-h urine sample collected during the year covered by the FFQ. The FFQ-25 covered a different period of time than the biomarker and may estimate the protein intake well, but this cannot be assessed on an individual level by one urinary sample from each participant. Classification in the same or adjacent quintile by the two dietary methods was similar to $68 \%$ found among young Danish women ${ }^{4}$ and higher than 59\% found in Danish women aged 40-64 years ${ }^{3}$. When the women were classified into quintiles of protein intake estimated from the FFQ-25, we observed a significant increasing trend in 'true' intake (estimated from the FD) and a significant trend of increasing urinary nitrogen with increasing quintile.

The correlation between retinol intake estimated from the two dietary methods was modest but significant, and within the range found by others; both lower correlations $^{26}$ and higher correlations ${ }^{4,22}$ have been reported. The sensitivity of being classified in the lowest quintile was low, but it seems that the FFQ-25 is capable of separating women into quintiles of retinol intake. The 'true' mean intake (from the FD) was significantly higher in quintile 5 compared with quintile 1 and there was a significant trend. Thus it seems that even though the correlation was weak, the questionnaire is able to separate low retinol consumers from high consumers. Total intake did not differ between the two dietary methods. The correlation was stronger and sensitivity was higher than for dietary intake alone. The information on retinol in dietary supplements is better defined than the content of the diet; therefore it is crucial to register dietary supplement use by brand name in epidemiological studies. There was no correlation between total intake and plasma retinol. This was not surprising because plasma retinol is believed to be useful as an indicator of intake only at low intake level ${ }^{33}$. In populations with higher intake, retinyl esters reflect intake. We tried to measure these, but the results were much higher than those found in the literature, about 40 times, and so were not reliable.

Folic acid intake estimated by the two dietary methods did not differ, except for folic acid from the unadjusted intake. Significant correlations between 0.35 and 0.57 were found by comparison of the two dietary methods, and the highest correlations were found for folic acid from dietary supplements and energy-adjusted total intake. This was slightly lower than the correlations found among non-pregnant Danish women ${ }^{4}$, but similar to the findings among pregnant Finnish women ${ }^{22}$. Sensitivity and specificity of correct classification into the first quintile were high for energy-adjusted intake of the nutrient. The highest sensitivity found in the present study was for total folic acid intake per $10 \mathrm{MJ}$, for which $77 \%$ of subjects were classified correctly into the two lowest quintiles and $74 \%$ into the two highest quintiles.
There was a significant trend of higher folic acid intake estimated from the FD for persons in each quintile than from the FFQ-25. Quintile 1 was nearly different from quintile 5 for folic acid from the diet, but for the biologically more interesting total intake, the difference was markedly different $(P<0.0001)$; the 'true' intake in the fifth quintile was almost twice as large as for the first quintile. Total folic acid intake was significantly correlated with erythrocyte folic acid level. The correlation coefficients were of the same size for both dietary methods, thus they seem to have equivalent validity. Erythrocyte folic acid is a long-term biomarker of intake, and this biomarker was expected to reflect intake estimated from the FFQ-25, which was completed 2-3 months before the blood sample was taken. There was a significant trend in erythrocyte folic acid level in each quintile of intake and quintile 1 was significantly different from quintile 5. As described for retinol, it is crucial to take into account intake of dietary supplements. These are very popular especially among pregnant women.

Intake of $n-3$ fatty acids was one third larger when estimated from the FFQ-25 than when estimated from the FD. The estimates were weak but significantly correlated between the two dietary methods, and both estimates of $n-3$ fatty acid intakes were significantly correlated with the erythrocyte EPA content. Others have also found a significant correlation between erythrocyte level and intake estimated from an $\mathrm{FFQ}^{34}$. Estimation of sensitivity showed that the questionnaire seems capable of classifying the participants into the two lowest quintiles. There was a significant increasing trend in erythrocyte EPA content with increasing quintile of intake estimated from the FFQ-25. Women in quintile 1 of intake estimated from the FFQ-25 had significantly lower erythrocyte EPA content than women in the 5th quintile, but there was no difference in 'true' intake. There are several reasons that could explain the low correlation between the two dietary methods. Fish are rarely eaten by pregnant Danish women; of the 88 women in the present study, 64 (73\%) answered in the FFQ-25 that fish was eaten less than once a week as hot meals and $45 \%$ consumed fish on bread less than once a week. Therefore women who did not consume their monthly fish in the recording week will have underestimated their average daily fish intake, and women who did eat their monthly fish in the recording week will have an overestimated daily average intake by the FD. Another explanation could be that the standard portion sizes used to estimate fish intake from the FFQ-25 were too large for Danish women. In the future these problems will be investigated.

\section{Implications}

The estimated sensitivities and specificities may have an applicability in future aetiological studies based on the DNBC that address relationships between disease phenomena on the one hand and the nutrients examined in the 
present study on the other. Relatively simple methods for correcting relative risks for exposure misclassification in a $2 \times 2$ table have been developed ${ }^{35}$. However, such corrected estimates should be used with great caution because the models rely on assumptions which may not always hold, particularly that that there is no misclassification of disease status and that the sensitivity and specificity are equal in the groups with and without the disease (i.e. non-differential misclassification).

The sensitivity for being correctly classified into the lowest, the two lowest, the highest and the two highest quintiles with FD estimates as the gold standard was lowest for retinol and $n-3$ fatty acid intakes, and particularly for these nutrients one should consider to use intake below the second quintile as the exposure.

\section{Conclusion}

Comparison with weighed FD and biomarkers showed that the FFQ-25 administered to 100000 Danish women gives reasonably valid estimated intakes of protein, retinol and folic acid, especially when the women are classified into high and low consumers of the nutrients. Estimated intake of $n-3$ fatty acids seems to be overestimated by the FFQ-25. Future work will compare standard portion sizes with the individual portion sizes for fish in the weighed FD.

\section{Acknowledgements}

We acknowledge the late Professor Brittmarie Sandström for her important contribution and excellent supervision until her death. Jóhanna Torfadóttir and Camilla Trapp Damsgaard are also thanked for their excellent contribution in relation to processing of the food records. Biochemical analyses were undertaken at the Royal Veterinary and Agricultural University Copenhagen, Denmark; Environmental Medicine, Odense, Denmark; Department of Clinical Chemistry, Odense, Denmark; and Division of Human Nutrition, Wageningen University, The Netherlands. Financial support for the validation study was obtained from the March of Dimes Birth Defects Foundation (\#6-FY96-0240, 97-0553, 97-0521, 98-642, 00407), the Danish National Research Foundation the European Union (QLK1-2000-00083), Novo Nordic Foundation and the Health Foundation.

\section{References}

1 Olsen J, Melbye M, Olsen SF, Sorensen TI, Aaby P, Andersen AM, et al. The Danish National Birth Cohort - its background, structure and aim. Scandinavian Journal of Public Health 2001; 29(4): 300-7.

2 Overvad K, Tjonneland A, Haraldsdottir J, Ewertz M, Jensen OM. Development of a semiquantitative food frequency questionnaire to assess food, energy and nutrient intake in Denmark. International Journal of Epidemiology 1991; 20(4): 900-5.

3 Tjonneland A, Overvad K, Haraldsdottir J, Bang S, Ewertz M, Jensen OM. Validation of a semiquantitative food frequency questionnaire developed in Denmark. International Journal of Epidemiology 1991; 20(4): 906-12.

4 Friis S, Kruger Kjaer S, Stripp C, Overvad K. Reproducibility and relative validity of a self-administered semiquantitative food frequency questionnaire applied to younger women. Journal of Clinical Epidemiology 1997; 50(3): 303-11.

5 Barker DJ, Gluckman PD, Godfrey KM, Harding JE, Owens JA, Robinson JS. Fetal nutrition and cardiovascular disease in adult life. Lancet 1993; 341(8850): 938-41.

6 Langley SC, Jackson AA. Increased systolic blood pressure in adult rats induced by fetal exposure to maternal low protein diets. Clinical Science 1994; 86(2): 217-22.

7 Langley Evans SC, Gardner DS, Jackson AA. Maternal protein restriction influences the programming of the rat hypothalamic-pituitary-adrenal axis. Journal of Nutrition 1996; 126(6): $1578-85$.

8 Langley Evans SC, Welham SJ, Sherman RC, Jackson AA. Weanling rats exposed to maternal low-protein diets during discrete periods of gestation exhibit differing severity of hypertension. Clinical Science 1996; 91(5): 607-15.

9 Rothman KJ, Moore LL, Singer MR, Nguyen US, Mannino S, Milunsky A. Teratogenicity of high vitamin A intake. New England Journal of Medicine 1995; 333(21): 1369-73.

10 Miller RK, Hendrickx AG, Mills JL, Hummler H, Wiegand UW. Periconceptional vitamin A use: how much is teratogenic? Reproductive Toxicology 1998; 12(1): 75-88.

11 Berry RJ, Li Z, Erickson JD, Li S, Moore CA, Wang H, et al. Prevention of neural-tube defects with folic acid in China. China-US Collaborative Project for Neural Tube Defect Prevention. New England Journal of Medicine 1999; 341(20): 1485-90.

12 Prevention of neural tube defects: results of the MRC Vitamin Study. MRC Vitamin Study Research Group. Lancet 1991; 338(8760): 132-7.

13 Olsen SF. Marine $n-3$ fatty acids ingested in pregnancy as a possible determinant of birth weight: a review of the current epidemiologic evidence. Epidemiologic Reviews 1993; 15(2): 399-413.

14 Olsen SF, Secher NJ, Tabor A, Weber T, Walker JJ, Gluud C. Randomised clinical trials of fish oil supplementation in high risk pregnancies. Fish Oil Trials In Pregnancy (FOTIP) Team. British Journal of Obstetrics and Gynaecology 2000; 107(3): 382-95.

15 Bailey LB. Dietary reference intakes for folate: the debut of dietary folate equivalents. Nutrition Reviews 1998; 56(10): $294-9$.

16 Moore LL, Bradlee ML, Singer MR, Rothman KJ, Milunsky A. Folate intake and the risk of neural tube defects: an estimation of dose-response. Epidemiology 2003; 14(2): $200-5$.

17 Willett WC, Lenart E. Reproducibility and validity of foodfrequency questionnaires. In: Willett WC, ed. Nutritional Epidemiology. New York: Oxford University Press, 1998; 101-47.

18 Staud F, Fendrich Z, Hartl J, Jindrova O, Laznicek M, Different transfers of $N$-acetyl- $p$-aminobenzoic acid and $p$-aminobenzoic acid across the placenta and the small intestine in rats. Journal of Drug Targeting 1998; 5(3): 207-13.

19 Derewlany LO, Knie B, Koren G. Human placental transfer and metabolism of $p$-aminobenzoic acid. Journal of Pharmacology and Experimental Therapeutics 1994; 269(2): 761-5.

20 Parrish LA, Marshall JA, Krebs NF, Rewers M, Norris JM. Validation of a food frequency questionnaire in preschool children. Epidemiology 2003; 14(2): 213-7. 
21 Stevenson RE, Allen WP, Pai GS, Best R, Seaver LH, Dean J, et al. Decline in prevalence of neural tube defects in a highrisk region of the United States. Pediatrics 2000; 106(4): $677-83$.

22 Erkkola M, Karppinen M, Javanainen J, Räsänen L, Knip M, Virtanen SM. Validity and reproducibility of a food frequency questionnaire for pregnant Finnish women. American Journal of Epidemiology 2001; 154(5): 466-76.

23 Subar AF, Thompson FE, Kipnis V, Midthune D, Hurwitz P, McNutt S, et al. Comparative validation of the Block, Willett, and National Cancer Institute food frequency questionnaires: the Eating at America's Table Study. American Journal of Epidemiology 2001; 154(12): 1089-99.

24 Day N, McKeown N, Wong M, Welch A, Bingham S. Epidemiological assessment of diet: a comparison of a 7-day diary with a food frequency questionnaire using urinary markers of nitrogen, potassium and sodium. International Journal of Epidemiology 2001; 30(2): 309-17.

25 Kroke A, Klipstein-Grobusch K, Voss S, Moseneder J, Thielecke F, Noack R, et al. Validation of a self-administered food-frequency questionnaire administered in the European Prospective Investigation into Cancer and Nutrition (EPIC) study: comparison of energy, protein, and macronutrient intakes estimated with the doubly labeled water, urinary nitrogen, and repeated 24-h dietary recall methods. American Journal of Clinical Nutrition 1999; 70(4): 439-47.

26 Lorentzen B, Drevon CA, Endresen MJ, Henriksen T. Fatty acid pattern of esterified and free fatty acids in sera of women with normal and pre-eclamptic pregnancy. British Journal of Obstetrics and Gynaecology 1995; 102(7): 530-7.

27 Ocke MC, Bueno-de-Mesquita HB, Pols MA, Smit HA, van Staveren WA, Kromhout D. The Dutch EPIC food frequency questionnaire. II. Relative validity and reproducibility for nutrients. International Journal of Epidemiology 1997; 26(Suppl. 1): S49-58.

28 Callmer E, Riboli E, Saracci R, Akesson B, Lindgarde F. Dietary assessment methods evaluated in the Malmo food study. Journal of Internal Medicine 1993; 233(1): 53-7.

29 Rothenberg E. Validation of the food frequency questionnaire with the 4-day record method and analysis of 24-h urinary nitrogen. European Journal of Clinical Nutrition 1994; 48(10): 725-35.

30 Klipstein-Grobusch K, den Breeijen JH, Goldbohm RA, Geleijnse JM, Hofman A, Grobbee DE, et al. Dietary assessment in the elderly: validation of a semiquantitative food frequency questionnaire. European Journal of Clinical Nutrition 1998; 52(8): 588-96.

31 Bingham SA, Gill C, Cassidy A, Runswick SA, Oakes S, Lubin R, et al. Validation of dietary assessment methods in the UK arm of EPIC using weighed records, and 24-hour urinary nitrogen and potassium and serum vitamin $\mathrm{C}$ and carotenoids as biomarkers. International Journal of Epidemiology 1997; 26(Suppl. 1): S137-51.

32 Pijls LT, de Vries H, Donker AJ, van Eijk JT. Reproducibility and biomarker-based validity and responsiveness of a food frequency questionnaire to estimate protein intake. American Journal of Epidemiology 1999; 150(9): 987-95.

33 Hunter D. Biochemical indicators of dietary intake. In: Willett WC, ed. Nutritional Epidemiology. New York : Oxford University Press, 1998; 174-243.

34 Olsen SF, Hansen HS, Sandström M, Jensen B. Erythrocyte levels compared with reported dietary intake of marine $n-3$ fatty acids in pregnant women. British Journal of Nutrition 1995; 73(3): 387-95.

35 Willett WC. Correction for the effects of measurement error. In: Willett WC, ed. Nutritional Epidemiology. New York: Oxford University Press, 1998; 302-20. 